\title{
Suction Pearl: Standardization of the Suction Heights of Suction Syringes
}

\author{
Muhammed Mukhtar (iD) ${ }^{1, *}$ \\ ${ }^{1}$ Mukhtar Skin Centre, Katihar Medical College Road, 854105, Katihar, India \\ "Corresponding author: Mukhtar Skin Centre, Katihar Medical College Road, 854105, Katihar, India. Email: drmmukhtar20@gmail.com
}

Received 2020 June 06; Revised 2021 June 23; Accepted 2021 August 23.

Keywords: Suction Syringe, Suction Height, Timing, Diameter, Radius, Blister

\section{Dear editor,}

Suction syringes are utilized to produce blisters for epidermal grafts, as well as for treating localized and stable vitiligo with better cosmetic acceptability. However, the suction process should be fast to save time. The 3-way cannulasyringe can produce blisters within 1 to $2 \mathrm{~h}$ (1). Moreover, the failure of this device at -300 to $-400 \mathrm{mmHg}$ to produce a suction blister and the incidence of incomplete blisters at the site are seen in about 20 to $30 \%$ of cases $(2,3)$. The success rate is improved by the application of heat, intralesional injection of normal saline and local anesthetic agents over the donor site. Thus, the 3-way cannula-syringe is a little cumbersome and time-consuming device. On the other hand, a modified dispensable syringe applied directly onto the donor area of skin produces blisters in approximately $30 \mathrm{~min}$ to one $\mathrm{h}$ at $6.5 \mathrm{~cm}$ (length/height of the suction column in the suction syringe) of the suction height at -1atmospheric pressure (-760mm Hg at sea level), which was arbitrarily fixed (4). Assuming that there is no significant impact of suction height on timing of blister production. For this, a number of syringes are modified after cutting the barrel transversely with a heated surgical blade proximal to the needle hub end and making a hole at different level in the piston to insert a metal rod/needle for sustaining the suction process. These modified syringes are faster and more successful in the suction procedure without significant failure, if it is applied over the immovable surface in an air-tight manner. However, the higher height of the syringe is not good for device stability and successful blister production over the site. For this, the size of the suction syringe and 3-way cannula-suction syringe is reduced to get a stable device by utilizing a small disposable syringe cup for a faster suction process $(5,6)$. The min- imum height of the suction and its impact on the blister production are still not well documented in the literature. To keep this view and positive experience with the little suction cup, two sets of disposable suction syringes at its various suction heights are applied to standardize the suction heights for getting flawless and complete blisters.

Two sets of disposable syringes are used. Set A is composed of four $3,5,10$, and $20 \mathrm{~mL}$ syringes with their respective radii of $5,6,8$, and $10 \mathrm{~mm}$, and set B is composed of five $10 \mathrm{~mL}$ syringes with an $8 \mathrm{~mm}$ radius. All syringes are cut and modified into suction devices. In set $\mathrm{A}$, the suction heights are fixed at their radii $(+5 \mathrm{~mm}$, the length of projected piston top) at 10, 11, 13, and $15 \mathrm{~mm}$, and openings are made in their pistons with a heated $16 \mathrm{G}$ needle. That is the reason, $5 \mathrm{~mm}$ is added to the suction heights of set A syringes to manage the projected part of the piston top in the barrel. In the syringes of set $\mathrm{B}$, the suction heights are fixed at 1, 2, 3, 5, $6 \mathrm{~cm}$, and openings are made in their pistons with the heated needle. A $16 \mathrm{G}$ needle is used for making openings in pistons and sustaining the suction process by inserting it in the piston openings until the completion of the blister or for $1 \mathrm{~h}$ (Figure $1 \mathrm{~A}$ - D).

Before the suction procedures, liquid paraffin or antibiotic ointment is applied around the piston top and the rim of the suction barrels to make the device more airfixed. With all aseptic precautions, the syringe is applied tightly over the donor site on the shins of the leg, and the piston is pulled up to the height of the opening in the piston. Then, the $16 \mathrm{G}$ needle is inserted into the opening, and the suction process is continued for $1 \mathrm{~h}$. The syringes of set A are applied over the right shin (Figure $2 \mathrm{~A}$ - E), and then, the syringes of the Set $\mathrm{B}$ are applied over the left shin because it is hard, flat, and stable that gives stability to the de- 

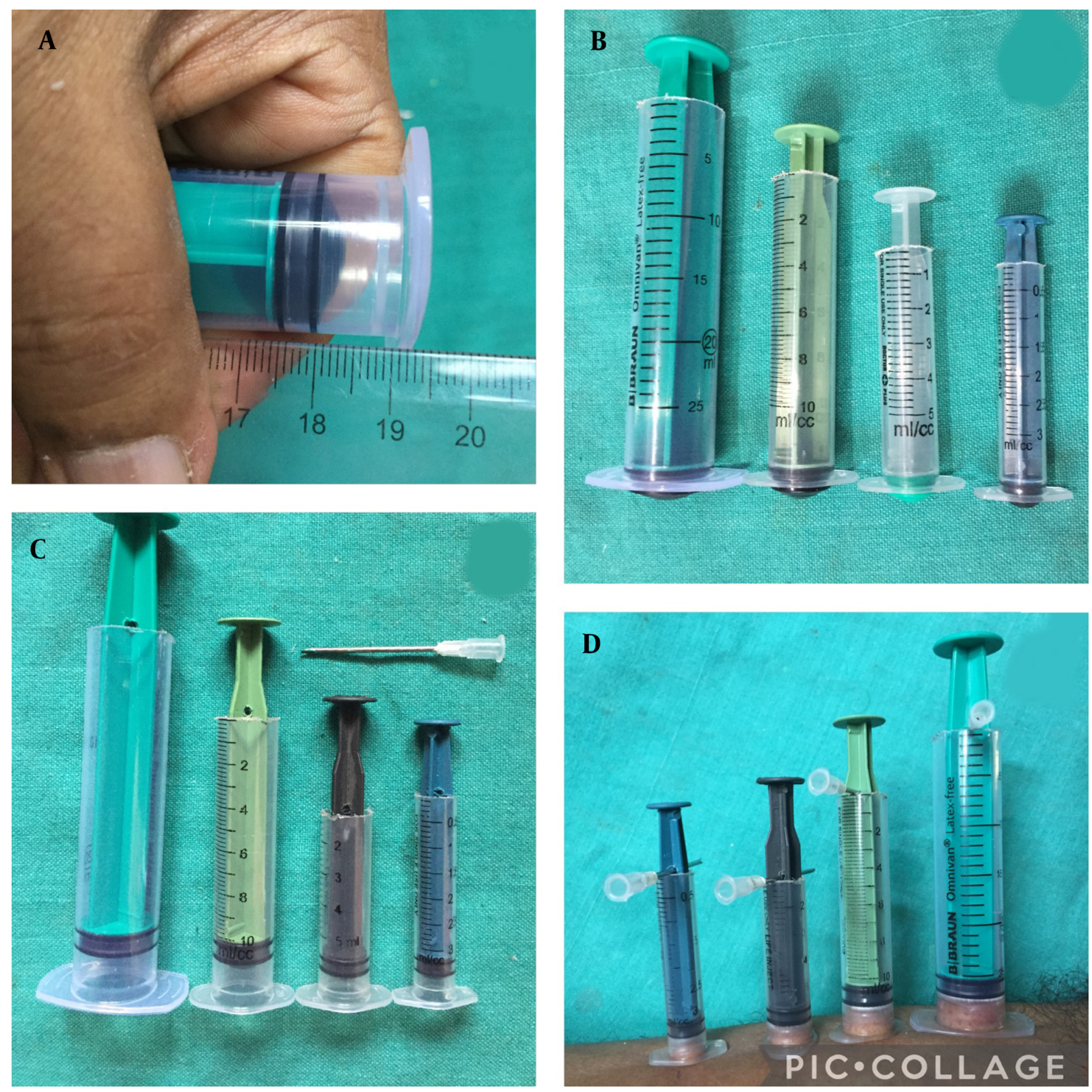

Figure 1. A - D, Different steps are required for making a set of suction syringes.

vice for better and fast suction (Figure 3A-D). The changes over the suction sites were properly noted.

In observation, vesicles are produced within 15 to 20 min, which start to merge within 30 to $40 \mathrm{~min}$, and blisters are formed after about 50 to $60 \mathrm{~min}$ at both shins. Blisters are produced at all suction sites over the shin. In set A, the $10 \mathrm{~mL}$ (at the suction height of $13 \mathrm{~mm}$ and $20 \mathrm{~mL}$ (at the suction height of $15 \mathrm{~mm}$ ) syringes (Table 1), and in set B, the $10 \mathrm{~mL}$ syringe (at suction height of $10 \mathrm{~mm}$ )(Table 2 ), um- bilicated blisters are produced because the projected tip of the piston top touches the center of the sucked donor sites. The suction procedure is well tolerated, and no intrablister hemorrhage or rupture of the blisters is seen. The suction height (the column if more than its radius and less than its diameter) of the syringe has no significant impact on the suction process regarding the duration of blister formation, and shape, size, color (intrablister hemorrhage), and integrity (rupture) of blisters. The time taken by all suction 

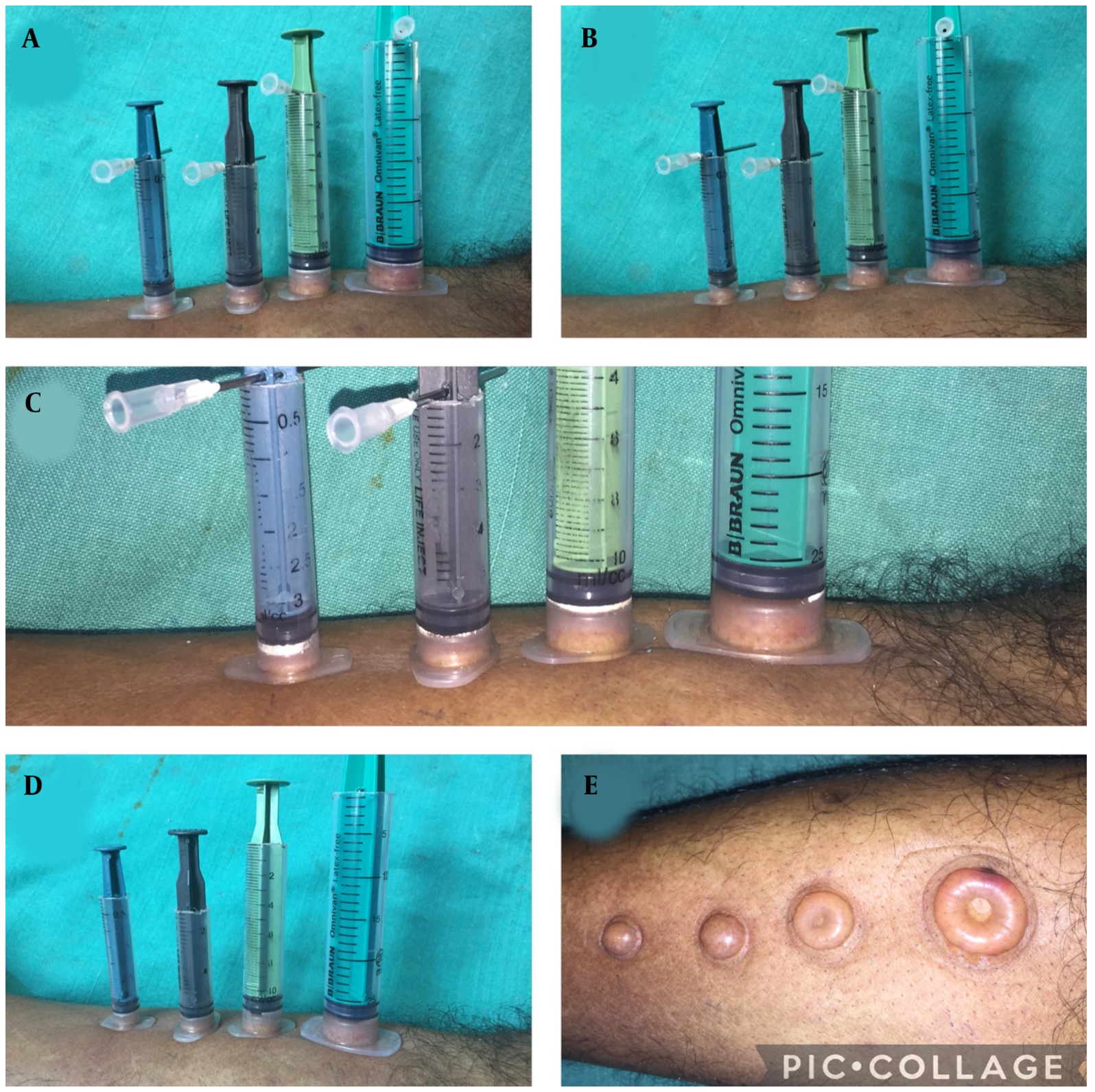

Figure 2. A-E, The syringes of set A at the suction heights of their different radii for suction over the right shin in different phases of suction.

syringes is proportional to an earlier report of suction timing at the suction height of $6.5 \mathrm{~cm}$. In conclusion, the minimum suction height of the syringes should be roughly proportional to their diameter (not to the radius of the suction cup due to piston head projection) to get a complete and intact blister. Thus, a modified disposable syringe set is a faster and an effective suction tool even at the suction height of its radius, if it is applied in an airtight manner on an immovable site. Based on these findings, the disposable suction syringe can be made small for better stability and success of the device during the procedure.

\section{Footnotes}

Authors' Contribution: This letter was prepared by the only author.

Conflict of Interests: The author declared no conflicts of interest. 

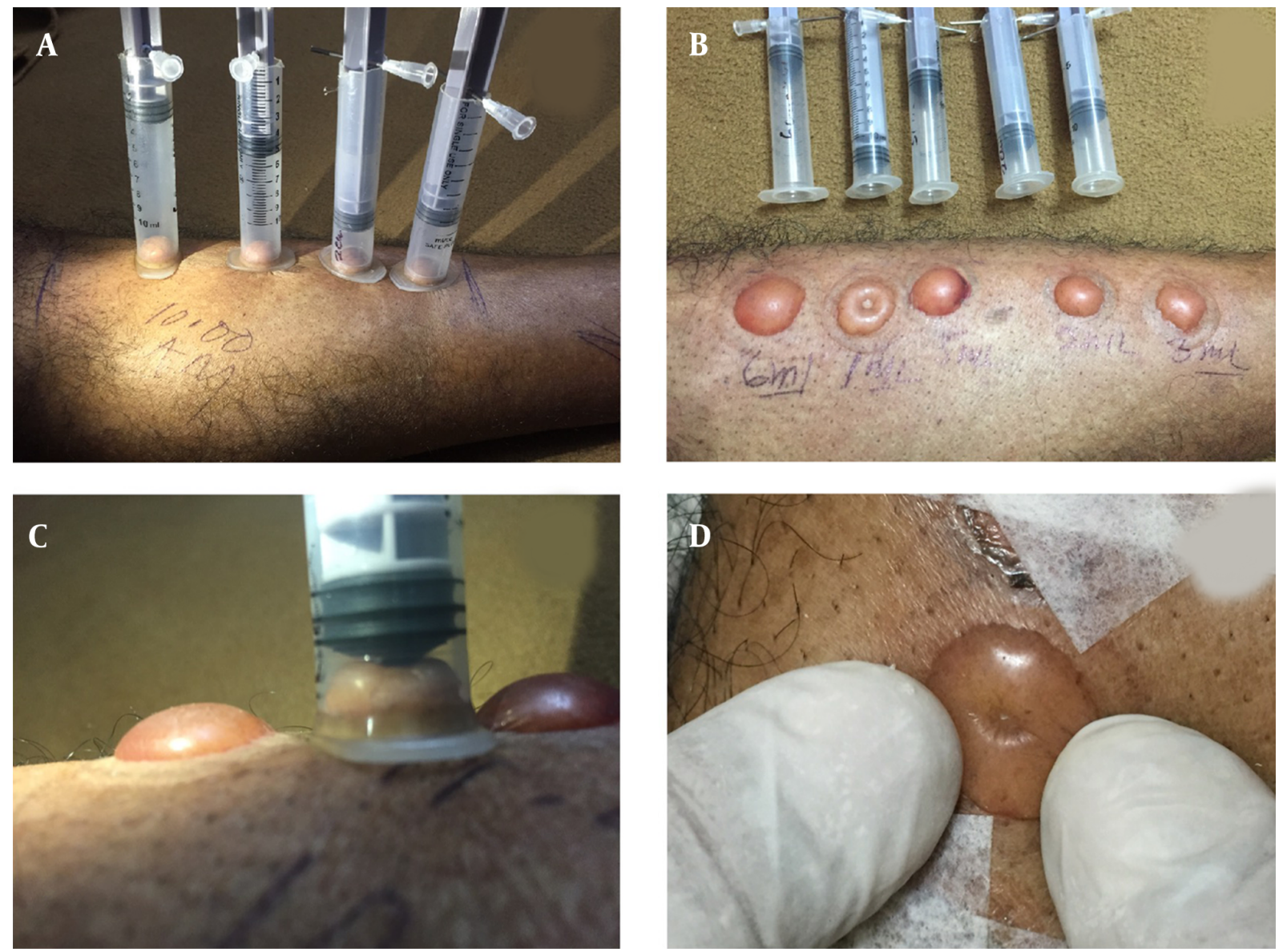

Figure 3. A-D, The syringes of set $B$ at the different suction heights for suction over the left shin in different phases of suction.

Table 1. The Radii, Piston Head Projection, Suction Height, and Blister of the Set A Suction Syringes

\begin{tabular}{|c|c|c|c|c|}
\hline Syringe, mL & Radius (1), mm & Piston Head Projection (2), mm & Suction Height $(1+2), \mathrm{mm}$ & Blister \\
\hline 3 & 5 & 5 & 10 & Complete \\
\hline 5 & 6 & 5 & 11 & Complete \\
\hline 10 & 8 & 5 & 13 & Umbilicated \\
\hline 20 & 10 & 5 & 15 & Umbilicated \\
\hline
\end{tabular}

Table 2. The Radii, Piston Head Projection, Suction Height, and Blister of the Set B Suction Syringes (10 mL)

\begin{tabular}{|c|c|c|c|c|}
\hline Syringes of $10 \mathrm{~mL}$ & Radius, mm & Piston Head Projection, $\mathrm{mm}$ & Suction Height, cm & Blister \\
\hline 1. & 8 & 5 & 1 & Umbilicated \\
\hline 2. & 8 & 5 & 2 & Complete \\
\hline 3. & 8 & 5 & 3 & Complete \\
\hline 4. & 8 & 5 & 5 & Complete \\
\hline 5. & 8 & 5 & 6 & Complete \\
\hline
\end{tabular}


Funding/Support: There was no funding/support.

\section{References}

1. Gupta S, Kumar B. Suction blister induction time: 15 minutes or 150 minutes? Dermatol Surg. 2000;26(8):754-6. doi: 10.1046/j.15244725.2000.00050.x. [PubMed: 10940062].

2. Laxmisha C, Thappa DM. Reliable site for suction blister induction and harvesting. Indian J Dermatol Venereol Leprol. 2005;71(5):321-4. doi: 10.4103/0378-6323.16781. [PubMed: 16394455].
3. Anbar TS, Moftah NH, El-Khayyat MAM, El-Fakahany HM, AbdelRahman AT, Saad EK. Syringes versus Chinese cups in harvesting suction-induced blister graft: A randomized split-body study. Int JDermatol. 2018;57(10):1249-52. doi: 10.1111/ijd.14040. [PubMed: 29797713].

4. Mukhtar M, Singh S, Shukla VK, Pandey SS. Surgical pearl: Suction syringe for epidermal grafting.J Am Acad Dermatol.1997;37(4):638-9. doi: 10.1016/s0190-9622(97)70184-1. [PubMed: 9344206].

5. Mukhtar M. Disposable syringe cup for 3-way cannula-syringe suction. J Am Acad Dermatol. 2020. doi: 10.1016/j.jaad.2020.04.043. [PubMed: 32320765].

6. Mukhtar M. Surgical pearl: Small suction syringe for producing blister. J skin Stem cell. 2020;7(3). doi: 10.5812/jscc.106614. 